\title{
Improved Multibody Dynamics for Investigating Energy Dissipation in Train Collisions Based on Scaling Laws
}

\author{
Heng Shao, ${ }^{1}$ Ping Xu, ${ }^{1}$ Shuguang Yao, ${ }^{1}$ Yong Peng, ${ }^{1}$ Rui Li, ${ }^{1}$ and Shizhong Zhao ${ }^{2}$ \\ ${ }^{1}$ Key Laboratory of Traffic Safety on Track, Ministry of Education, School of Traffic \& Transportation Engineering, \\ Central South University, Changsha, Hunan 410075, China \\ ${ }^{2}$ China South Locomotive and Rolling Stock Industry, Sifang Locomotive and Rolling Stock Co., Ltd., Qingdao, Shandong 266111, China
}

Correspondence should be addressed to Ping Xu; xuping@csu.edu.cn

Received 14 January 2016; Accepted 15 May 2016

Academic Editor: Tai Thai

Copyright (C) 2016 Heng Shao et al. This is an open access article distributed under the Creative Commons Attribution License, which permits unrestricted use, distribution, and reproduction in any medium, provided the original work is properly cited.

\begin{abstract}
This study aimed to investigate energy dissipation in train collisions. A $1 / 8$ scaled train model, about one-dimensional in longitudinal direction, was used to carry out a scaled train collision test. Corresponding multibody dynamic simulations were conducted using traditional and improved method model (IMM) in ADAMS. In IMM, the connection between two adjacent cars was expressed by a nonlinear spring and energy absorbing structures were equivalently represented by separate forces, instead of one force. IMM was able to simulate the motion of each car and displayed the deformation of structures at both ends of the cars. IMM showed larger deformations and energy absorption of structures in moving cars than those in stationary cars. Moreover, the asymmetry in deformation proportion in main energy absorbing structures decreased with increasing collision speed. The asymmetry decreased from $11.69 \%$ to $3.60 \%$ when the collision speed increased from $10 \mathrm{~km} / \mathrm{h}$ to $36 \mathrm{~km} / \mathrm{h}$.
\end{abstract}

\section{Introduction}

The finite element (FE) method is increasingly used to study the large elastic-plastic deformation problems in train collisions. However, the calculation process is complex and timeconsuming. On the other hand, multibody dynamic methods can predict the gross motion of a train set and the total structure deformations faster and with ease. Multibody dynamic methods are more efficient in solving the crashworthiness design, which is about a whole train's deformation and energy absorbing distribution.

Many studies have been carried out on elastic collision by the multibody dynamics method. Kane studied the collision of a multibody system by considering friction problems through discrete methods [1]. Lankarani and Pereira presented a method of multiplane rigid-body systems with friction for states after collision and considered changes in the sliding direction by the Poisson coefficient [2]. Wittenburg introduced the graph theory of building multibody systems and discussed contact collision dynamics of multibody system [3]. Featherstone discussed a method of positive/inverse dynamics and contacts for open/closed loop multi-rigid-body systems collision [4]. However, multi-rigidbody system models could not achieve accurate requirements of the real system. Flexible multibody system dynamics were therefore used to investigate large deformation problem under impact loading. Likins proposed the hybrid coordinate method to build floating flexible-body coordinate systems, with the location and shape of flexible body considered to be a combination of rigid-body's large global motion and elastic deformation relative to the synthetic floating coordinate [5]. Ahmed studied the flexible multibody system with large deformation by using absolute coordinates [6]. Wittbrodt et al. described a rigid FE method by using similarity transformation and rigid-flexible coupling system dynamic equations generated from hinge coordinate automatically [7]. Carvalho et al. used plastic hinges to represent structural deformations of vehicles [8]. Jacobsen used one- and three-dimensional multibody dynamic models for his studies and proposed collision energy management (CEM) to reduce secondary damage [9]. Lu studied the influence of the number of vehicles in a train on energy absorption by one-dimensional multibody simulation [10]. Dias and Pereira used a one-dimensional 
multibody model to study optimization methods for crashworthiness design by multiobjective genetic algorithms [11]. Han and Koo investigated the crash simulation of highspeed train with an obstacle in three dimensions by using multibody dynamics and studied derailment and override [12]. Zhou et al. studied three-dimensional dynamic models, influence of pitching frequencies, heights of mass centre, and collision mass on override and derailment analysis about two kinds of crashed freight trains on a curve $[13,14]$. Yang et al. investigated the dynamic response of a train-bridge system subjected to earthquakes in a full three-dimensional model [15]. The secondary impact injury of a railway vehicle occupant during collision was studied by Xie and Tian using one-dimensional coupling collision model in longitudinal direction to obtain dynamic response for each car [16]. However, the coupling of large global motion and flexible-body deformation complicates modeling and analysis of dynamics for the flexible multibody system modeling. Compared with research on rigid-body dynamics, the research is scanty on large deformation crashworthiness for flexible multibody systems.

A prototype test is expensive, difficult, and timeconsuming, which is why most studies on train collision are carried out through simulation. Scaled model tests should therefore be used. Scaled model test is widely used in crashworthiness study of airplanes, automobiles, ships, and other structures due to its advantages in implementation, repeatability, and reliability. Kao and Barley conducted a 1/10 and a 1/2 automobile scaled model test to study the automobile crashworthiness $[17,18]$. Lowe et al. studied the crashworthiness of buses on $1 / 25$ scaled model test [19]. Jiang et al. studied scaled collision law of metal cone specimen [20]. Wang et al. studied local damage effects in a concrete target under the impact of projectiles [21]. Xu et al. showed that scaled models represent real models if appropriate similarity coefficients are applied [22].

In this study, scaled model experiments were conducted to investigate energy dissipation in train collisions. The corresponding multibody dynamic simulations were conducted by TMM (traditional method model) and IMM (improved method model) in ADAMS. The energy absorption design equation was improved by introducing a dynamic asymmetry coefficient.

\section{Methodology}

2.1. Scaling and Similarity Method. Dimensionless analysis is commonly used for testing models practice in situations where equations relating to the parameters of a process are unknown. In order to scale-test models correctly, coefficients accounting for similarity in material properties, geometry, load, and dynamic properties are calculated based on the Buckingham $\pi$ Theory $[22,23]$, which can be described as follows:

$$
f\left(q_{1}, q_{2}, \ldots, q_{n}\right)=0 .
$$

Assuming that $q_{n}, q_{n-1}, \ldots, q_{n-k+1}$ are $k$ independent base physical quantities, there are $k$ groups of real numbers $a_{n, i}, a_{n-1, i}, \ldots, a_{n-k+1, i} . n-k q_{i}$ can be expressed as

$$
q_{i}=\pi_{i} q_{n}^{a_{n, i}} q_{n-1}^{a_{n-1, i}} \cdots q_{n-k+1}^{a_{n-k+1, i}}, \quad i=1,2, \ldots, n-k .
$$

Equation (2) can be converted to

$$
\pi_{i}=\frac{q_{i}}{q_{n}^{a_{n, i}} q_{n-1}^{a_{n-1, i}} \cdots q_{n-k+1}^{a_{n-k+1, i}}} .
$$

Since $\pi_{i}$ represent dimensionless quantities, the index is $a_{n, i}, a_{n-1, i}, \ldots, a_{n-k+1, i}$.

All material property similarity ratios are set as 1.0 using dimensional analysis. The similarity coefficients of geometry and mechanics parameters are presented in Table 1.

2.2. Design of Scaled Model Test. The scaled train model was designed using scaling and similarity method. The design of corresponding small structures of the train proved difficult. Therefore, the scale model was a simple one-dimensional mechanical equivalent to the train model in the longitudinal direction. Each car was simplified into an iron block and the energy absorption structures with plastic deformation were made with honeycombs and the buffer between two cars was made with rubber. The mechanical properties of these materials were close to the energy absorption structures and draft gear. Their mechanical properties are shown in Figure 1. Quasi-static compressive force-deflection curves of one kind of honeycomb $(100 \mathrm{~mm} * 100 \mathrm{~mm} * 80 \mathrm{~mm})$ (Figure $1(\mathrm{~b})$ ) and rubber $(10.3 \mathrm{~mm} * 10.5 \mathrm{~mm} * 8.3 \mathrm{~mm}$ ) (Figure 1(d)) were obtained by using Mechanical Testing and Simulation (MTS).

A scale factor $S$ of $1 / 8$ was used. The design of the scaled model is shown in Table 2. In order to prevent unbalanced distribution of the load, the honeycomb was put on both sides symmetrically. Large deformations mainly occur in the first and second cars [11]; therefore, honeycombs were only placed on a single side between cars 2 and 3, cars 3 and 4, and cars 4 and 5 . The rubber and honeycombs after car 5 were removed, as shown in Figure 2(a). The numbers in Figure 2(a) correspond to those in Table 2.

Based on the railway safety test of "EN 15227-2008" [24], the collision occurs between a moving and a stationary train at a speed of $25 \mathrm{~km} / \mathrm{h}$, as shown in Figure 2(b). The moving train was represented by a moving car, whose mass was equal to the whole scaled train. The energy absorbing structures in front of the moving car were the same as the structures in the head car of the scaled model. All objects were placed in a 3-meter track to prevent movement in any direction except longitudinally.

During the experiment, a moving car impacted the left side of the model. The honeycombs were compressed and absorbed energy, and the iron blocks moved forward with the moving car. A high-speed digital camera, with a sampling interval of $0.2 \mathrm{~ms}$ (corresponding to 5000 frames/second), was used to capture the deformation of the scaled train model.

2.3. Simulation. For a marshalling train, when a longitudinal collision occurs, not only longitudinal impact load tension 
TABLE 1: Scaling parameters.

\begin{tabular}{lccc}
\hline Category & Independent parameter & Dimension & Similarity factor \\
\hline \multirow{4}{*}{ Material } & Stress $(\sigma)$ & $F L^{-2}$ & 1.0 \\
& Strain $(\varepsilon)$ & - & 1.0 \\
& Elastic modulus $(E)$ & $F L^{-2}$ & 1.0 \\
& Poisson's ratio $(\mu)$ & - & 1.0 \\
Geometry & Density $(\rho)$ & $F L^{-4} T^{2}$ & 1.0 \\
& Length $(L)$ & $L$ & $S$ \\
Energy & Area $(S)$ & $L^{2}$ & $S^{2}$ \\
& Volume $(V)$ & $L^{3}$ & $S^{3}$ \\
Dynamic & Elastic and plastic energy, kinetic energy $(E)$ & $F L$ & $S^{3}$ \\
& Mass $(m)$ & $F T^{2} L^{-1}$ & $S^{3}$ \\
& Load $(F)$ & $F$ & $S^{2}$ \\
& Time $(t)$ & $T$ & $S$ \\
\hline
\end{tabular}

${ }^{*} L, F$, and $T$ are base quantity dimensions. $L$ : length; $F$ : force; $T$ : time; $S$ : similarity factor.

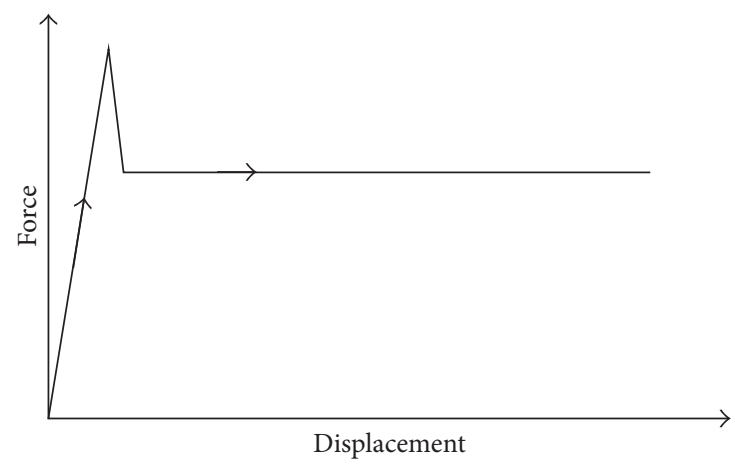

(a) Energy absorption structures

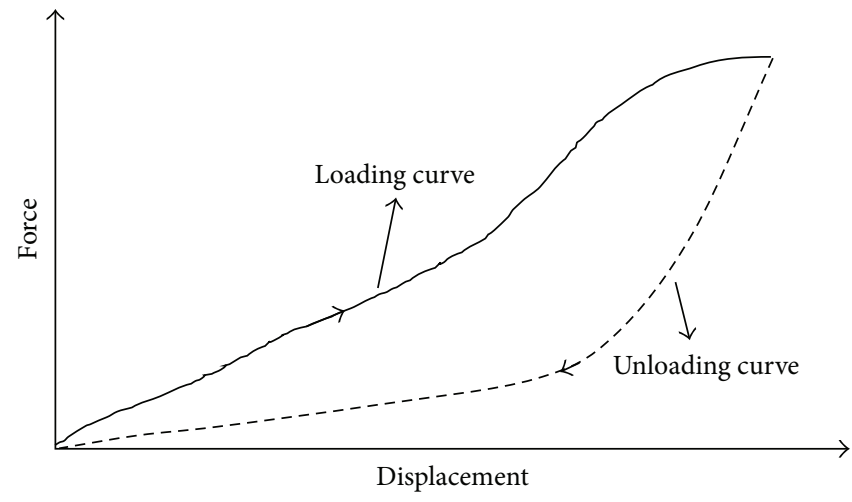

(c) Buffer

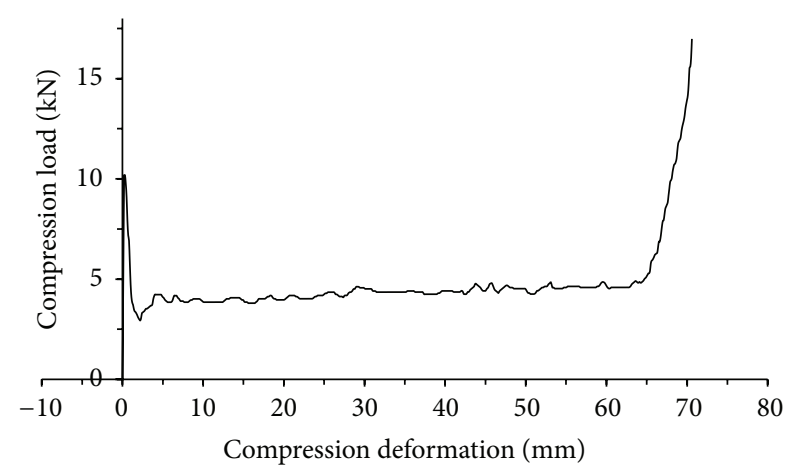

(b) Honeycomb

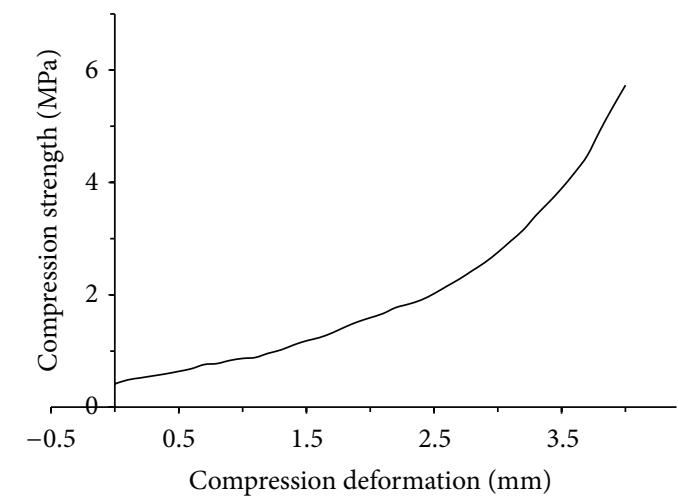

(d) Rubber

FIGURE 1: Mechanical property curves.

but also compression movements are caused, as well as verti$\mathrm{cal}$ and lateral loads and the torque of the three directions. The impact force and energy are great. Ignoring the overriding and derailment, each car body mainly produces a longitudinal motion and deformation. Therefore, the one-dimensional multibody dynamic model was used to simulate the train collision.

The buffer is a recoverable elastic element, whereas collapsed tubes, main energy absorbing structures, and car bodies are unrecoverable plastic elements. Reasonable 


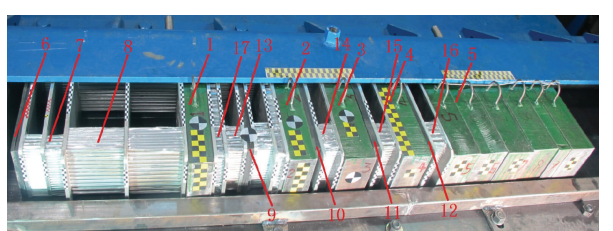

(a) Design of scaled model

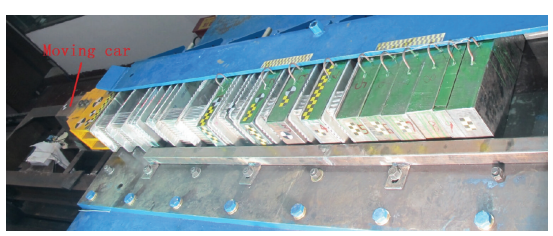

(b) Experiment scene

FIGURE 2: Scaled train collision test.

TABLE 2: Design of scaled model.

\begin{tabular}{|c|c|c|c|c|c|}
\hline Number & Structure & Parameter name & Real value & Scaled value & Design in experiment \\
\hline 1 & \multirow{8}{*}{ Cars } & Car 1 mass & $46.6 \mathrm{t}$ & $91 \mathrm{~kg}$ & \multirow{8}{*}{$\begin{array}{c}\text { Iron blocks } \\
\text { Size: cross-sectional area } 200 * 440 \mathrm{~mm}^{2}\end{array}$} \\
\hline 2 & & Car 2 mass & $50.9 \mathrm{t}$ & $99 \mathrm{~kg}$ & \\
\hline 3 & & Car 3 mass & $56.0 \mathrm{t}$ & $109 \mathrm{~kg}$ & \\
\hline \multirow[t]{2}{*}{4} & & Car 4 mass & $48.5 \mathrm{t}$ & $95 \mathrm{~kg}$ & \\
\hline & & Car 5 mass & $50.0 \mathrm{t}$ & $98 \mathrm{~kg}$ & \\
\hline \multirow[t]{3}{*}{5} & & Car 6 mass & $53.3 \mathrm{t}$ & $104 \mathrm{~kg}$ & \\
\hline & & Car 7 mass & $56.0 \mathrm{t}$ & $109 \mathrm{~kg}$ & \\
\hline & & Car 8 mass & $47.2 \mathrm{t}$ & $92 \mathrm{~kg}$ & \\
\hline \multirow{2}{*}{6} & \multirow{2}{*}{ Buffer in head car } & Compression & $87 \mathrm{~mm}$ & $10.875 \mathrm{~mm}$ & Rubber \\
\hline & & Max. force & $600 \mathrm{kN}$ & $9.375 \mathrm{kN}$ & Size: $200 * 400 * 20 \mathrm{~mm}^{3}$ \\
\hline \multirow[b]{2}{*}{7} & \multirow{2}{*}{$\begin{array}{l}\text { Collapsed tube in } \\
\text { head car }\end{array}$} & Length & $500 \mathrm{~mm}$ & $62.5 \mathrm{~mm}$ & Two honeycombs \\
\hline & & $\begin{array}{l}\text { Steady compression force of } \\
\text { plastic deformation }\end{array}$ & $600 \mathrm{kN}$ & $9.375 \mathrm{kN}$ & $\begin{array}{l}\text { Size: } 190 * 270 * 78 \mathrm{~mm}^{3} \\
\quad \text { Strength: } 0.18 \mathrm{MPa}\end{array}$ \\
\hline \multirow[b]{2}{*}{8} & \multirow{2}{*}{$\begin{array}{c}\text { Main energy } \\
\text { absorbing structure in } \\
\text { head car }\end{array}$} & Length & $3000 \mathrm{~mm}$ & $375 \mathrm{~mm}$ & Two honeycombs \\
\hline & & $\begin{array}{l}\text { Steady compression force of } \\
\text { plastic deformation }\end{array}$ & $1100 \mathrm{kN}$ & $17.1875 \mathrm{kN}$ & $\begin{array}{l}\text { Size: } 190 * 160 * 400 \mathrm{~mm}^{3} \\
\text { Strength: } 0.56 \mathrm{MPa}\end{array}$ \\
\hline \multirow{2}{*}{$9-12$} & \multirow{2}{*}{ Buffer in middle car } & Compression & $100 \mathrm{~mm}$ & $12.5 \mathrm{~mm}$ & Rubber \\
\hline & & Max. force & $1000 \mathrm{kN}$ & $15.625 \mathrm{kN}$ & Size: $200 * 400 * 20 \mathrm{~mm}^{3}$ \\
\hline \multirow{2}{*}{$13-16$} & \multirow{2}{*}{$\begin{array}{l}\text { Collapsed tube in } \\
\text { middle car }\end{array}$} & Length & $500 \mathrm{~mm}$ & $62.5 \mathrm{~mm}$ & Two honeycombs \\
\hline & & $\begin{array}{l}\text { Steady compression force of } \\
\text { plastic deformation }\end{array}$ & $1000 \mathrm{kN}$ & $15.625 \mathrm{kN}$ & $\begin{array}{l}\text { Size: } 190 * 190 * 65 \mathrm{~mm}^{3} \\
\quad \text { Strength: } 0.44 \mathrm{MPa}\end{array}$ \\
\hline 17 & Car body & $\begin{array}{l}\text { Steady compression force of } \\
\text { plastic deformation }\end{array}$ & $1500 \mathrm{kN}$ & $23.4375 \mathrm{kN}$ & $\begin{array}{c}\text { A honeycomb } \\
\text { Size: } 190 * 440 * 20 \mathrm{~mm}^{3} \\
\text { Strength: } 0.27 \mathrm{MPa}\end{array}$ \\
\hline
\end{tabular}

nonlinear force elements should therefore be adopted to simulate their work status. After analyzing the characteristics of energy absorption structures, performance curves were drawn as force-displacement curves. Nonlinear springs were used to simulate the performance characteristics of energy absorption structures, which can be used to simulate any elastic-plastic deformation [14].

Using collision energy management (CEM), all energy absorption structures successively absorb energy in an orderly and controlled way. When a longitudinal collision occurs, the buffer produces elastic deformation to absorb energy. After the buffer reaches maximum stroke, the impact force triggers collapse of the tubes. Collapsed tubes produce plastic deformation to absorb energy. Then, the main energy absorbing structures were compressed, and finally car bodies were destroyed. The force-displacement curves between two cars were given according to work thresholds of energy absorption structures designed in Table 2.

Corresponding simulation was constructed using the ADAMS software. In the one-dimensional model, longitudinal motion and deformation were considered. Meanwhile, the buffers were modeled by nonlinear springs, taking their loading and unloading characteristics into account (Figure 1(c)). Considering collision safety, energy absorption structures should not only have good energy absorption characteristic, but also provide steady or almost steady compression force to avoid an excessively high rate of retardation. The steady compression force is very important to the design and prediction of retardation. Therefore, an ideal force-displacement curve was used to express its characteristic (Figure 1(a)). The force-displacement curve of the honeycomb used in test was almost steady. Collapsed tubes and main energy absorbing 


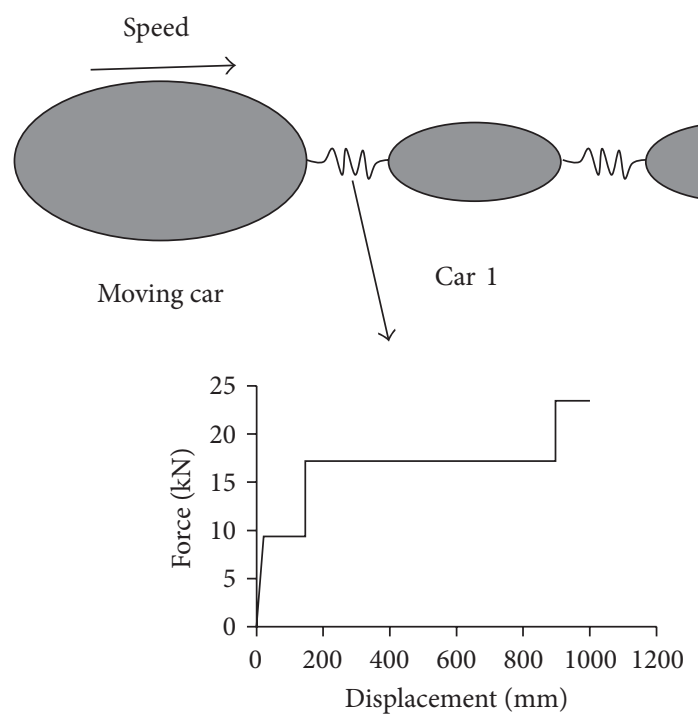

(a)
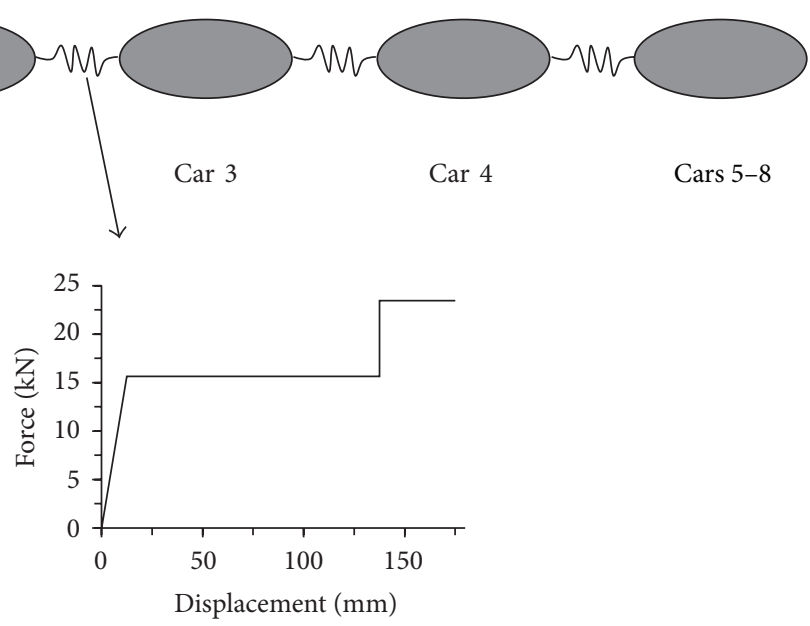

(b)

FIgUre 3: Traditional method model (TMM).

structures' peak forces were 1.5 times the steady compression forces. The friction coefficient between the train and rail was 0.1 .

According to the first-kind Lagrange equation, the equations for the one-dimensional dynamic model of motion can be written as follows:

$$
M_{i} \cdot \ddot{q}_{i}=F_{i}^{f}+F_{i}^{b}+F_{i}^{s},
$$

where $M_{i}$ is the mass of the car body; $q_{i}$ is the displacement of the car body; $F^{f}$ is the force of rolling friction; $F^{b}$ is the force of sliding friction; and $F^{s}$ is the nonlinear spring force between two cars.

We performed both traditional and improved multibody models of the experiment. For the traditional method model (TMM), the connection between two cars was expressed by a nonlinear force for both the head (Figure 3(a)) and the middle (Figure 3(b)) cars. The force combined the mechanical characteristics of the buffer and energy absorbing structures, but the peak forces of plastic deformation structures were not taken into account, which also influenced energy absorption. This would lead to a discrepancy between the experiment and simulation. Although the total deformation between two adjacent cars could be calculated by TMM, the deformation of structures at both ends of the cars was uncertain. Therefore, an improved method model (IMM) was used.

For IMM (Figure 4), each car body was divided into three: $M_{i 1}, M_{i 2}$, and $M_{i 3}$. Both ends of the cars were the deformation regions, and the mass of the deformation region was about one-tenth the original mass. The contact between head cars was buffer force (Figure 4(b)), and the connection force between two adjacent cars from car 1 to car 5 was another (Figure 4(c)). The deformation of energy absorbing structures in region 1 of head car was regarded as an inside force between the moving car and region 1 . Region 2 operated in a similar way. The force is shown in Figure 4(a). For other deformation regions from 3 to 10 in middle cars, the equivalent substituted force is shown in Figure 4(d). Equation (4) can be changed as follows:

$$
M_{i} \cdot \ddot{q}_{i}=F_{i}^{f}+F_{i}^{b}+F_{i}^{s}+F_{i}^{12}+F_{i}^{23}
$$

in which

$$
M_{i} \cdot \ddot{q}_{i}=M_{i 1} \cdot \ddot{q}_{i 1}+M_{i 2} \cdot \ddot{q}_{i 2}+M_{i 3} \cdot \ddot{q}_{i 3},
$$

where $F_{i}^{12}$ is the nonlinear force between $M_{i 1}$ and $M_{i 2}$ and $F_{i}^{23}$ is the nonlinear force between $M_{i 2}$ and $M_{i 3}$.

\section{Results}

The contact between the moving car and honeycomb was considered as time zero. The speed of the moving car was $22.8 \mathrm{~km} / \mathrm{h}(6.344 \mathrm{~m} / \mathrm{s})$ at time zero. The speed reduced from $25 \mathrm{~km} / \mathrm{h}$ to $22.8 \mathrm{~km} / \mathrm{h}$ before collision because of energy dissipation from friction between the rails and wheels of the moving car. Figure 5 shows the cases before collision, during collision, and after collision of honeycombs. The values of deformation and two corresponding simulations are shown in Tables 3 and 4, respectively. Only total deformations between adjacent cars were obtained in TMM; their location names are identical between Table 3 and IMM. For example, deformation between moving car and car 1 is named "regions 1 and 2 in total." A large deformation was found in regions 1 and 2 , but no deformation was seen in region 2 . In the simulation, slight deformation was found after region 2 in TMM and IMM. Collapsed tubes in region 1 and region 2 were condensed in the experiment and simulations. In addition, all data in simulations were larger than those in the experiment, and the results of TMM were slightly larger than those of IMM.

Figure 6 shows a comparison of the velocities between the experiment and simulations. The velocities of the experiment 
TABLE 3: Comparison of deformations between experiment and TMM.

\begin{tabular}{|c|c|c|c|c|c|}
\hline & Location & $\begin{array}{l}\text { Deformation for } \\
\text { experiment }(\mathrm{mm})\end{array}$ & $\begin{array}{l}\text { Deformation for } \\
\text { TMM (mm) }\end{array}$ & $\begin{array}{c}\text { Difference } \\
(\mathrm{mm})\end{array}$ & Relative error \\
\hline \multirow{2}{*}{ Regions 1 and 2 in total } & Collapsed tube & 116 & 125 & 9 & $7.83 \%$ \\
\hline & Main energy absorbing structure & 333 & 383 & 50 & $15.02 \%$ \\
\hline \multirow{2}{*}{ Regions 3 and 4 in total } & Collapsed tube & 0 & 2.2 & 2.2 & \\
\hline & Car body & 0 & 0 & 0 & \\
\hline Regions 5 and 6 in total & & 0 & 1 & 1 & \\
\hline Regions 7 and 8 in total & & 0 & 1 & 1 & \\
\hline Regions 9 and 10 in total & & 0 & 0 & 0 & \\
\hline
\end{tabular}

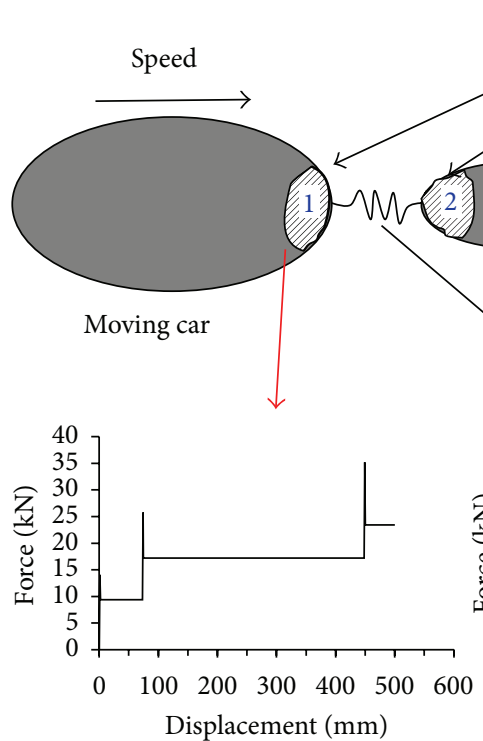

(a)

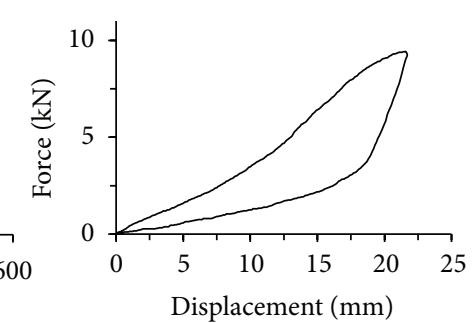

(b)

\section{Deformation region}

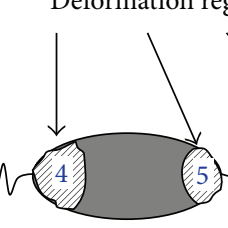

Car 2

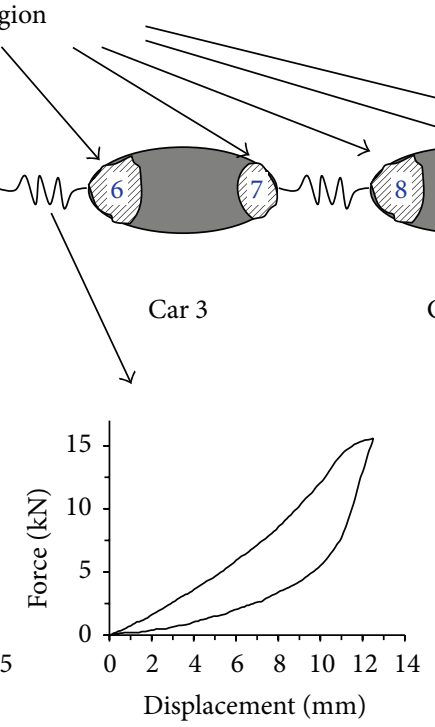

(c)
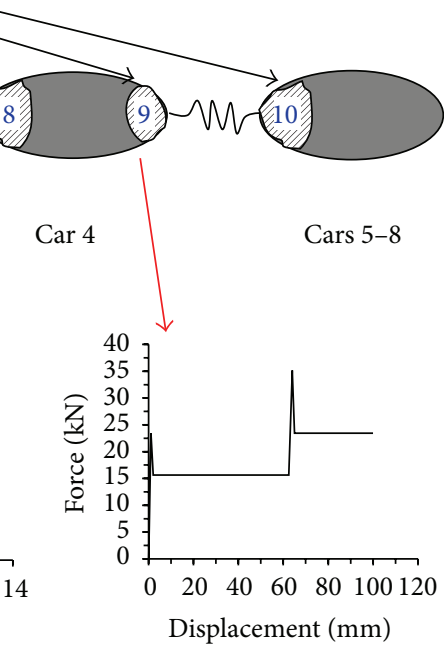

(d)

FIGURE 4: Improved method model (IMM).

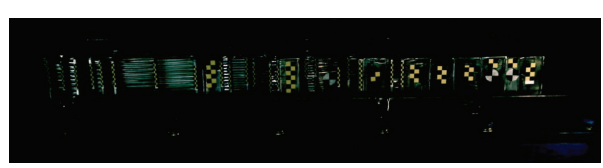

(a)

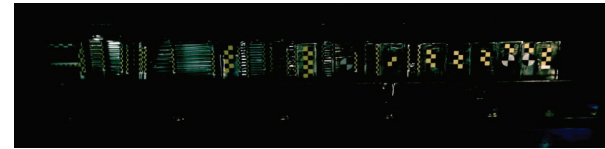

(b)

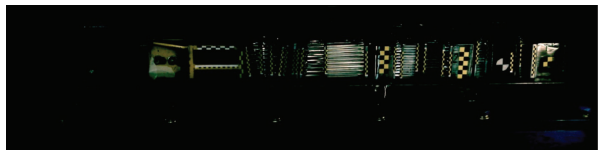

(c)

FIGURE 5: Impact process recorded by high-speed camera: (a) before collision; (b) during collision; (c) after collision.

were the speeds of marks on the centre of iron blocks captured by the camera. The velocities for TMM and IMM were the speeds of mass in the centre of each car. Figure 6 shows that the simulations agreed well with the experiment on the movement of each body. The experiment velocities were slightly higher than those of the simulations. The velocities of bodies at the stable moment are listed in Table 5. Figure 6 and Table 5 show that although the velocities in TMM at the stable time were much closer to the experiment than those of the IMM, the overall trend of velocity curves from IMM was more consistent with that of the experiment. The stable time of IMM is $0.164 \mathrm{~s}$ and differs from that of the experiment by 
TABLE 4: Comparison of deformations between experiment and IMM.

\begin{tabular}{|c|c|c|c|c|c|}
\hline & Location & $\begin{array}{l}\text { Deformation for } \\
\text { experiment }(\mathrm{mm})\end{array}$ & $\begin{array}{l}\text { Deformation for } \\
\text { IMM }(\mathrm{mm})\end{array}$ & $\begin{array}{c}\text { Difference } \\
(\mathrm{mm})\end{array}$ & Relative error \\
\hline \multirow{2}{*}{ Region 1} & Collapsed tube & 56 & 62.5 & 6.5 & $11.61 \%$ \\
\hline & Main energy absorbing structure & 199 & 224 & 25 & $12.56 \%$ \\
\hline \multirow{2}{*}{ Region 2} & Collapsed tube & 60 & 62.5 & 2.5 & $4.17 \%$ \\
\hline & Main energy absorbing structure & 134 & 150 & 16 & $11.94 \%$ \\
\hline \multirow{2}{*}{ Regions 1 and 2 in total } & Collapsed tube & 116 & 125 & 9 & $7.76 \%$ \\
\hline & Main energy absorbing structure & 333 & 374 & 41 & $12.31 \%$ \\
\hline \multirow{2}{*}{ Region 3} & Collapsed tube & 0 & 0.5 & 0.5 & \\
\hline & Car body & 0 & 0 & 0 & \\
\hline \multirow{2}{*}{ Region 4} & Collapsed tube & 0 & 0.6 & 0.6 & \\
\hline & Car body & 0 & 0 & 0 & \\
\hline \multirow{2}{*}{ Regions 3 and 4 in total } & Collapsed tube & 0 & 1.1 & 1.1 & \\
\hline & Car body & 0 & 0 & 0 & \\
\hline Regions 5 and 6 in total & & 0 & 2 & 2 & \\
\hline Regions 7 and 8 in total & & 0 & 1 & 1 & \\
\hline Regions 9 and 10 in total & & 0 & 3 & 3 & \\
\hline
\end{tabular}

TABLE 5: Velocities of bodies at stable time.

\begin{tabular}{|c|c|c|c|c|c|c|c|}
\hline & \multirow{2}{*}{ Stable time (s) } & \multicolumn{6}{|c|}{ Velocity $(\mathrm{m} / \mathrm{s})$} \\
\hline & & Moving car & Car 1 & Car 2 & Car 3 & Car 4 & Car 5 \\
\hline Experiment & 0.143 & 3.065 & 3.086 & 3.087 & 3.075 & 3.080 & 3.085 \\
\hline IMM & 0.164 & 2.902 & 2.887 & 2.881 & 2.881 & 2.895 & 2.904 \\
\hline TMM & 0.176 & 2.978 & 2.980 & 2.975 & 2.982 & 2.984 & 2.986 \\
\hline
\end{tabular}

*Stable time: the time when moving car's speed is equal to cars and after that moment moving car's speed is smaller than cars and honeycombs.

$0.021 \mathrm{~s}$ with an error of $14.69 \%$. For TMM, the difference value is $0.033 \mathrm{~s}$ and the error is $23.31 \%$.

Figure 7 shows the energy absorbing distribution of each region. R1, R2, R3, R4, R5-R6, R7-R8, and R9-R10 represent the energy absorbed by regions $1,2,3$, and 4 , regions 5 and 6 , regions 7 and 8, and regions 9 and 10, respectively. Table 4 shows that structures in IMM were compressed more severely and absorbed more energy than those in the experiment. This is due to the presence of vertical and lateral loads and the torque of three directions in the experiment, which were not considered in simulation. However, Figure 7 shows that the energy absorbing distribution was similar between the IMM and the experiment with the largest difference of proportion being $1.01 \%$ in $\mathrm{R} 2$.

In addition, such a conclusion can be obtained from the comparison between R1 and R2. Although two trains are symmetric with the collision interface, the deformation and energy absorption of structures in the moving car are larger than those in the stationary car.

\section{Discussions}

Similar to TMM in this study, many previous studies [916] have considered the connection and energy absorption structures at the end of two adjacent vehicles as a simple force, which made the deformation of structures at the ends of vehicle uncertain. In Jacobsen's study [9], a 3D dynamic model of train collisions was used with connection and energy absorption structures replaced by a force, as shown in Figure 8, and the corresponding real train collision experiments were carried out. Nonlinear characteristics of the draft gear and the initial peak value of plastic deformation were not considered. Therefore, the speed curves in the $3 \mathrm{D}$ dynamic model differ from those of the test. The greater the distance from the impact point, the bigger the difference of speed between the simulation and test.

In Lu's study [10], energy absorption design for the head car in a train was carried out, and the energy absorption for middle cars was designed based on the head car as follows:

$$
\begin{aligned}
E_{d} & =\frac{R_{1}}{2 f_{d}} \cdot k_{1}, \\
k_{1} & =\frac{1}{2} M_{1} v^{2}, \\
E_{i} & =R_{3} E_{d},
\end{aligned}
$$

where $E_{d}$ is energy absorption of head car; $R_{1}$ is energy absorption rate of collision interface in head car, and it is about $0.873 \sim 0.904 ; f_{d}$ is dynamic parameter and 1.2 is the suggested value; $k_{1}$ is kinetic energy of head car; coefficient 


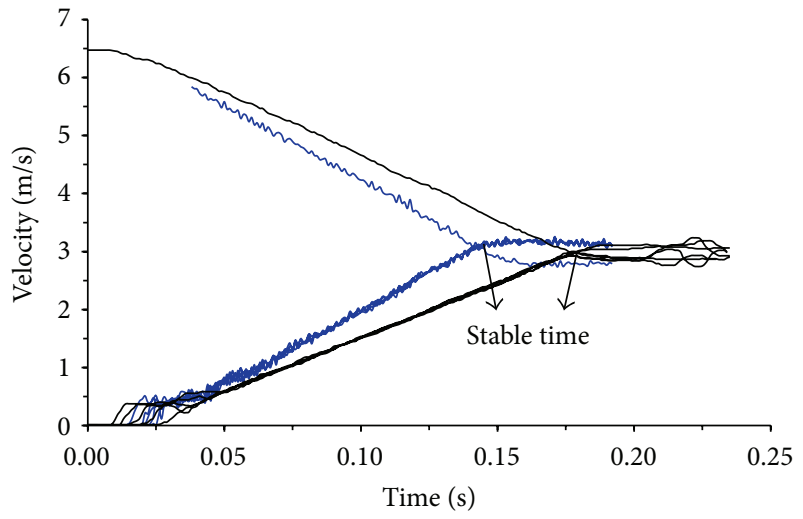

Experiment - TMM

(a)

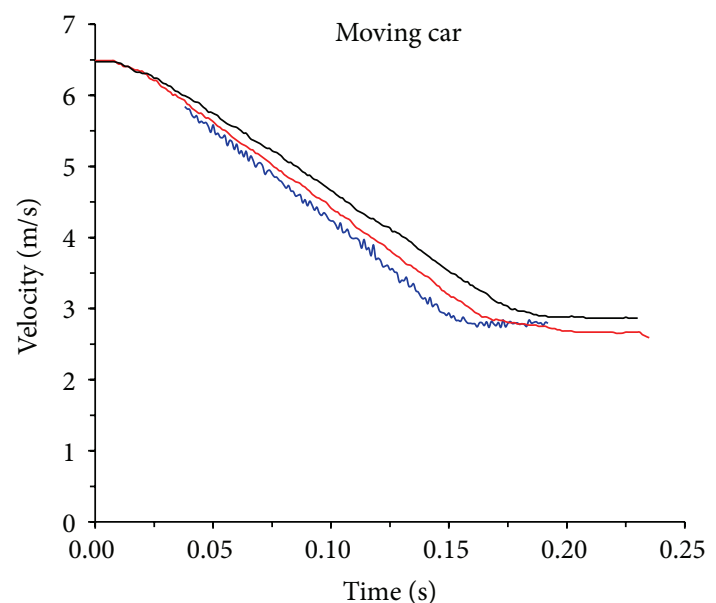

_ Experiment
_ IMM
TMM

(c)

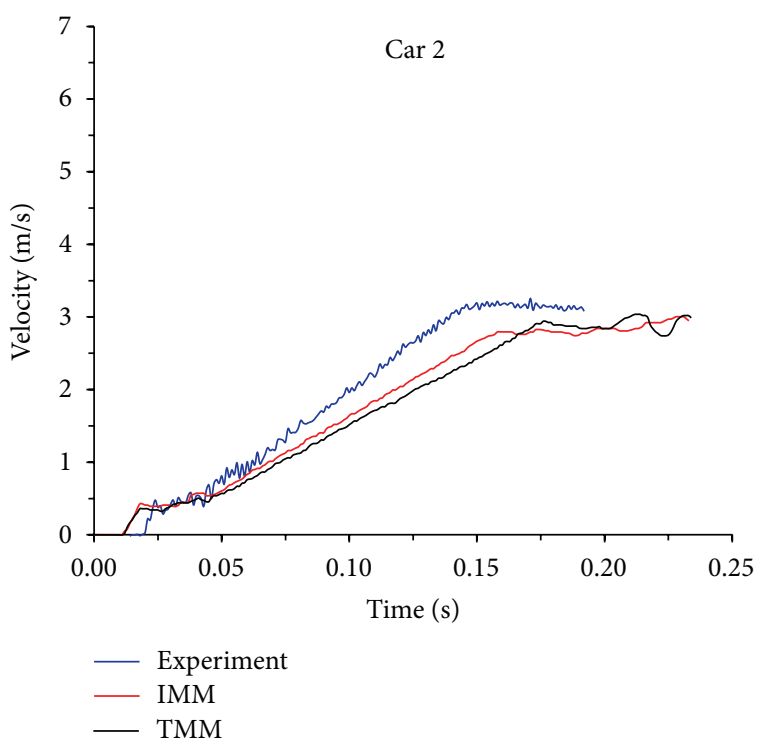

(e)

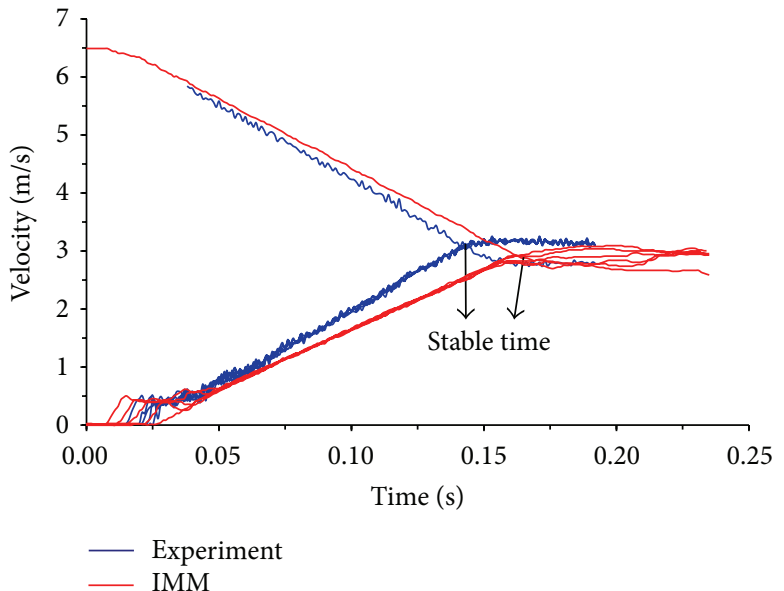

(b)

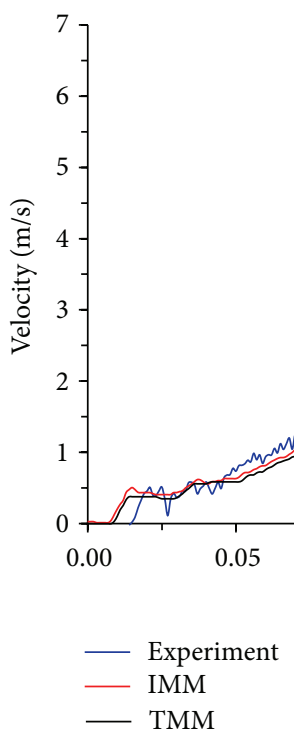

Car 1

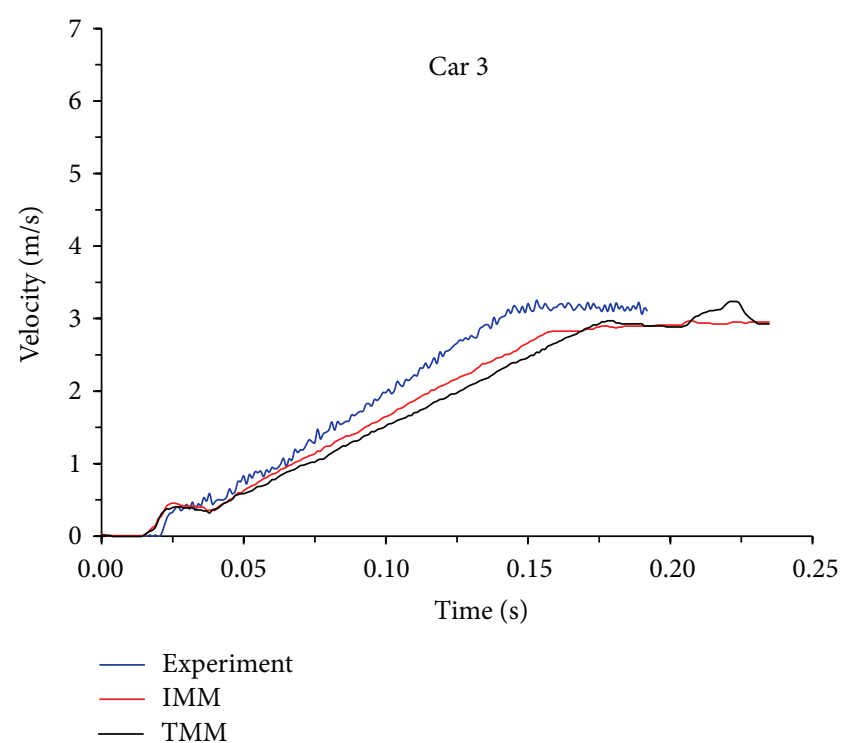

(f)

Figure 6: Continued. 


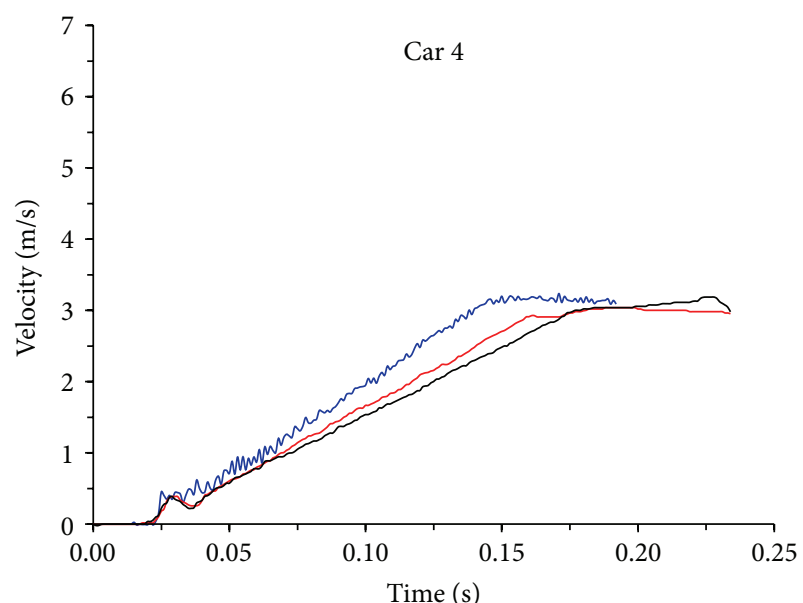

- Experiment

- IMM

- TMM

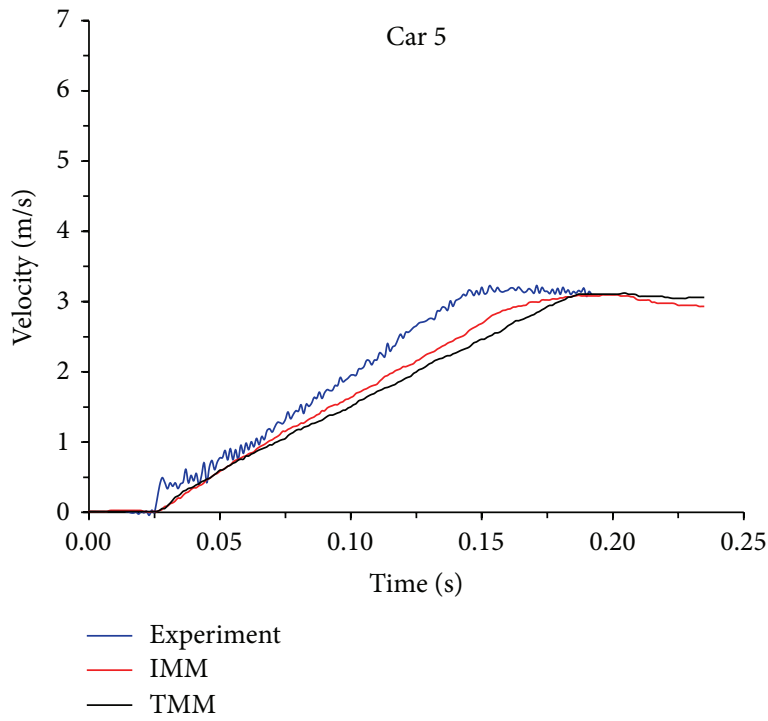

(h)

(g)

FIGURE 6: The comparison of velocity between experiment and simulations.

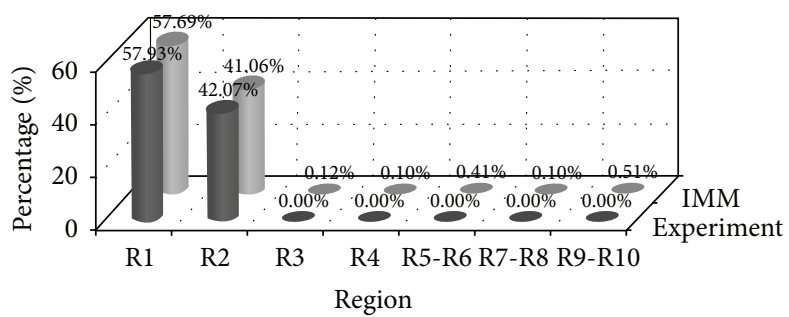

FIGURE 7: The energy absorbing distribution for experiment and IMM.

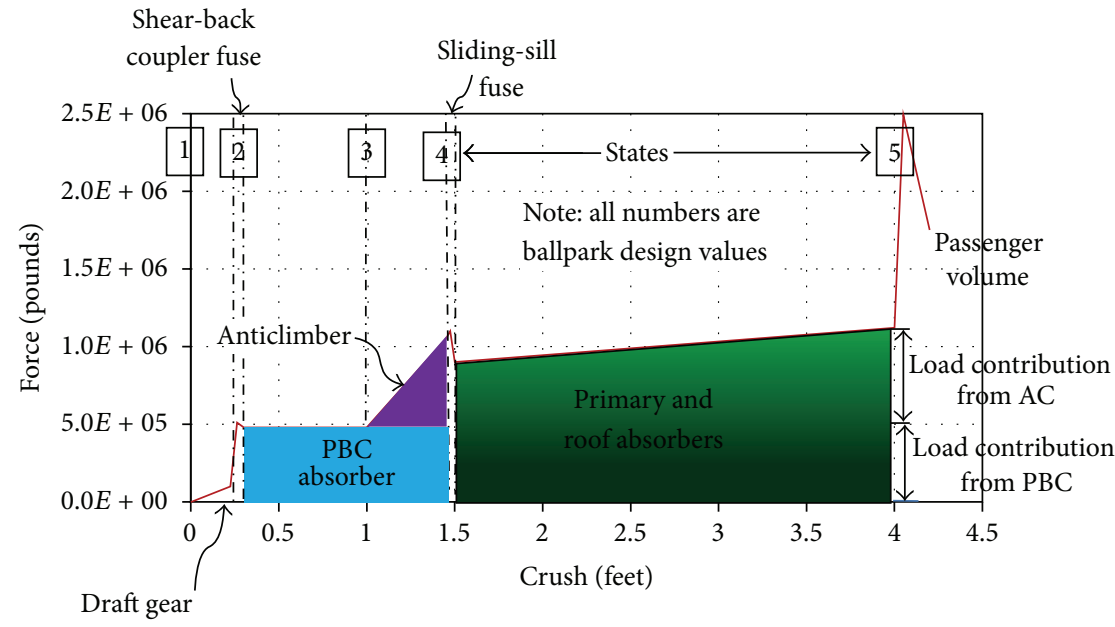

FIGURE 8: Force-crush characteristic.

2 indicates that the energy is evenly distributed between two head cars; $M_{1}$ is head car mass; $v$ is head car velocity; $E_{i}$ is energy absorption of a middle car; $R_{3}$ is the absorbed kinetic energy ratio of first and second collision interfaces.
According to this paper, a coefficient of value 2 in (7) is not suitable because energy is asymmetrically distributed. The asymmetry may be related to the collision speed and requires further investigation. The deformation and energy 
TABLE 6: Structure deformations and energy absorption of head car at different collision speeds.

\begin{tabular}{lccccccc}
\hline & \multirow{2}{*}{ Location } & \multicolumn{2}{c}{$10 \mathrm{~km} / \mathrm{h}$} & \multicolumn{2}{c}{$22.8 \mathrm{~km} / \mathrm{h}$} & \multicolumn{2}{c}{$36 \mathrm{~km} / \mathrm{h}$} \\
Region 1 & $\begin{array}{c}\text { Collapsed tube } \\
\text { Main energy } \\
\text { absorbing structure }\end{array}$ & 62.5 & 586 & 62.5 & 586 & 62.5 & 586 \\
\hline \multirow{2}{*}{ Region 2 } & $\begin{array}{c}\text { Collapsed tube } \\
\text { Main energy } \\
\text { absorbing structure }\end{array}$ & 62.5 & 277 & 224 & 3850 & 580 & 9969 \\
\hline
\end{tabular}

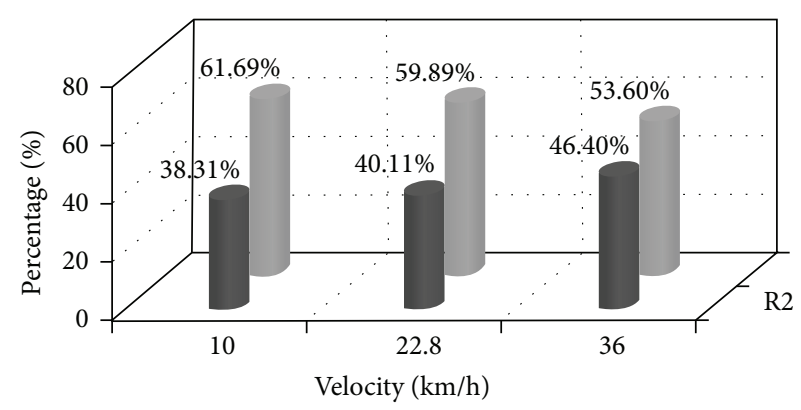

(a) Energy absorbing distribution

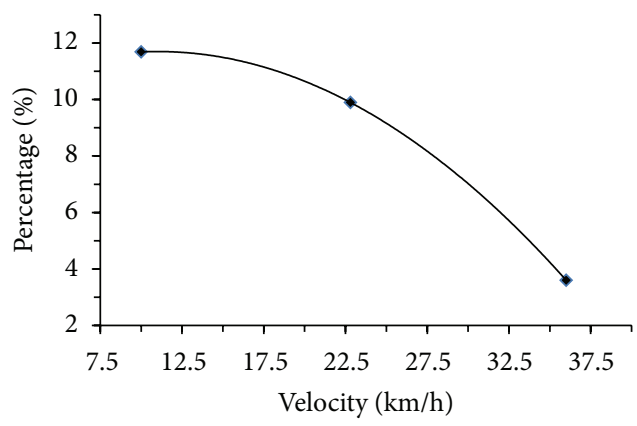

(b) Asymmetry trend of energy absorption

FIGURE 9: Energy absorption in main energy absorbing structure.

absorption of head car under three different collision speeds were also obtained by IMM (Table 6). As collapsed tubes were totally compressed, the asymmetry mainly occurred in two main energy absorbing structures. The energy absorbing distribution of two main structures at different velocities is shown in Figure 9(a), and the asymmetry trend is shown in Figure 9(b). The value of asymmetric deformation increases with the collision velocity according to Table 6 , but the value of asymmetry in percentage falls to $3.60 \%$ from $11.69 \%$. The asymmetry of energy absorption in head car is decreased with the increase of collision speed.

Therefore, (7) can be improved as follows:

$$
E_{d}=\frac{R_{1}}{2 f_{d}} \cdot k_{1} \cdot a,
$$

where $a$ is the dynamic asymmetry coefficient: the dynamic asymmetry coefficient of head car is represented by the main energy absorbing structure in head car, which is a conservative estimation. The mutual relationship between $a$ and $v$ is obtained by second-order polynomial fitting. Equation (10) can be replaced as follows:

$$
E_{d}=\frac{R_{1}}{2 f_{d}} \cdot \frac{1}{2} M_{1} v^{2} \cdot\left(-0.025 v^{2}+0.566 v+120.3\right) \% \text {. }
$$

In this study, a $1 / 8$ scaled model test of train collision was carried out, and an IMM was put forward. The comparison of IMM and TMM showed that the IMM is more reasonable. Lu's study about energy absorption design was improved based on the IMM by taking into account the asymmetry of energy absorption.
However, the current study has several limitations. The test was only carried out at $22.8 \mathrm{~km} / \mathrm{h}$. Higher and lower speeds should be used in future experiments. Only onedimensional experiment and simulation with large plastic deformation had been conducted. Three-dimensional studies need to be carried out. In addition, only a $1 / 8$ scaled model was studied. Full scaling models and other scaled factors should be used in future studies.

\section{Conclusions}

In this paper, a $1 / 8$ scaled train model was designed and scaled train collision test was carried out to investigate the energy dissipation of train collision. The scaled model was onedimensional in the longitudinal direction. The simulation of the experiment was conducted by TMM and IMM. In TMM, connection structures and energy absorption structures at the end of a vehicle were replaced by only one force. Conversely, in IMM, the connection between two cars was expressed by a nonlinear spring, and energy absorbing structures were represented by equivalent forces, instead of one force.

Simulation results showed that both models agreed with the experiment. However, IMM could better simulate the motion of each car in experiment and also displayed the deformation of structures at both ends of a car. Moreover, IMM showed that (for speed $10 \mathrm{~km} / \mathrm{h}$ to $36 \mathrm{~km} / \mathrm{h}$ ) although two trains are symmetric with the collision interface, the deformation and energy absorption of structures in the moving car are larger than those in the symmetric region in the stationary car. The asymmetry decreased with the increase of 
collision velocity. The energy absorption design equation in Lu's study was improved by introducing a dynamic asymmetry coefficient.

\section{Competing Interests}

The authors declare that there are no competing interests regarding the publication of this paper.

\section{Acknowledgments}

This research was undertaken at the Key Laboratory of Traffic Safety on Track, Ministry of Education, Central South University, China. The authors gratefully acknowledge the support from the National Natural Science Foundation of China (Grant no. U1334208) and the Nation Key Technology R\&D Program (Grant no. 2015BAG12B01) and the Key Projects of the Ministry of Education (Grant no. 113051A) and the Natural Science Foundation of Hunan (2015JJ3155) and the China Postdoctoral Science Foundation (2015M570691). The authors also thank LetPub (http://www.letpub.com/) for its linguistic assistance during the preparation of this paper.

\section{References}

[1] T. R. Kane, "A dynamics puzzle," Stanford Mechanics Alumni Club Newsletter, 1984.

[2] H. M. Lankarani and M. F. O. S. Pereira, "Treatment of impact with friction in planar multibody mechanical systems," Multibody System Dynamics, vol. 6, no. 3, pp. 203-227, 2001.

[3] J. Wittenburg, Dynamics of Multibody Systems, Springer, Berlin, Germany, 2nd edition, 2007.

[4] R. Featherstone, Rigid Body Dynamics Algorithms, Springer, New York, NY, USA, 2008.

[5] P. W. Likins, "Finite element appendage equations for hybrid coordinate dynamic analysis," International Journal of Solids and Structures, vol. 8, no. 5, pp. 709-731, 1972.

[6] A. S. Ahmed, Dynamics of Multibody Systems, Cambridge University Press, New York, NY, USA, 3rd edition, 2010.

[7] E. Wittbrodt, I. A. Wojcik, and S. Wojciech, Dynamics of Flexible Multibody Systems: Rigid Finite Element Method, Springer, Berlin, Germany, 2006.

[8] M. Carvalho, J. Ambrósio, and P. Eberhard, "Identification of validated multibody vehicle models for crash analysis using a hybrid optimization procedure," Structural and Multidisciplinary Optimization, vol. 44, no. 1, pp. 85-97, 2011.

[9] K. M. Jacobsen, Collision Dynamics Modeling of Crash Energy Management Passenger Rail Equipment, Tufts University, Boston, Mass, USA, 2008.

[10] G. Lu, "Energy absorption requirement for crashworthy vehicles," Proceedings of the Institution of Mechanical Engineers, Part F, vol. 216, no. 1, pp. 31-39, 2002.

[11] J. P. Dias and M. S. Pereira, "Optimization methods for crashworthiness design using multibody models," Computers \& Structures, vol. 82, no. 17-19, pp. 1371-1380, 2004.

[12] H.-S. Han and J.-S. Koo, "Simulation of train crashes in three dimensions," Vehicle System Dynamics, vol. 40, no. 6, pp. 435450, 2003.
[13] H. C. Zhou, J. J. Zhang, and M. Hecht, "Three-dimensional derailment analysis of a crashed city tram," Vehicle System Dynamics, vol. 51, no. 8, pp. 1200-1215, 2013.

[14] H. C. Zhou, W. B. Wang, and M. Hecht, "Three-dimensional override analysis of crashed railway multiple units," Vehicle System Dynamics, vol. 50, no. 4, pp. 663-674, 2012.

[15] X. Yang, H. H. Wang, and X. L. Jin, "Numerical analysis of a train-bridge system subjected to earthquake and running safety evaluation of moving train," Shock and Vibration, vol. 2016, Article ID 9027054, 15 pages, 2016.

[16] S. C. Xie and H. Q. Tian, "Dynamic simulation of railway vehicle occupants under secondary impact," Vehicle System Dynamics, vol. 51, no. 12, pp. 1803-1817, 2013.

[17] G. C. Kao, "A scale model study of crash energy dissipating vehicle structures," Tech. Rep. WR 68-3, Wyle Laboratories, El Segundo, Calif, USA, 1968.

[18] G. W. Barley and B. Mills, "A study of impact behaviour through the use of geometrically similar models," Tech. Rep., University of Birmingham, 1970.

[19] W. T. Lowe, S. T. S. Al-Hassani, and W. Johnson, "Impact behaviour of small scale model motor coaches," Proceedings of the Institution of Mechanical Engineers, vol. 186, no. 1, pp. 409419, 1972

[20] P. Jiang, C. J. Tian, R. Z. Xie, and D. S. Meng, "Experimental investigation into scaling laws for conical shells struck by projectiles," International Journal of Impact Engineering, vol. 32, no. 8, pp. 1284-1298, 2006.

[21] M. Wang, Z. Liu, Y. Qiu, and C. Shi, "Study on the similarity laws for local damage effects in a concrete target under the impact of projectiles," Shock and Vibration, vol. 2015, Article ID 585230, 16 pages, 2015.

[22] L. J. Xu, X. Z. Lu, S. T. Smith, and S. T. He, "Scaled model test for collision between over-height truck and bridge superstructure," International Journal of Impact Engineering, vol. 49, pp. 31-42, 2012.

[23] T. X. Yu and G. X. Lu, Energy Absorption of Structures and Materials, CRC Press, Boca Raton, Fla, USA, 2003.

[24] British Standard Institution, BS EN 15227-2008 Railway Application: Crashworthiness Requirement for Railway Vehicle Bodies, Rail Safety \& Standard Board, London, UK, 2008. 


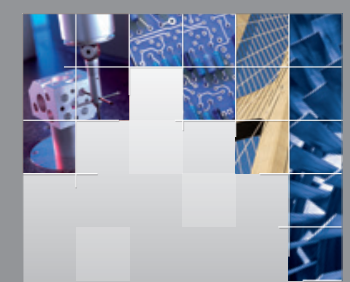

\section{Enfincering}
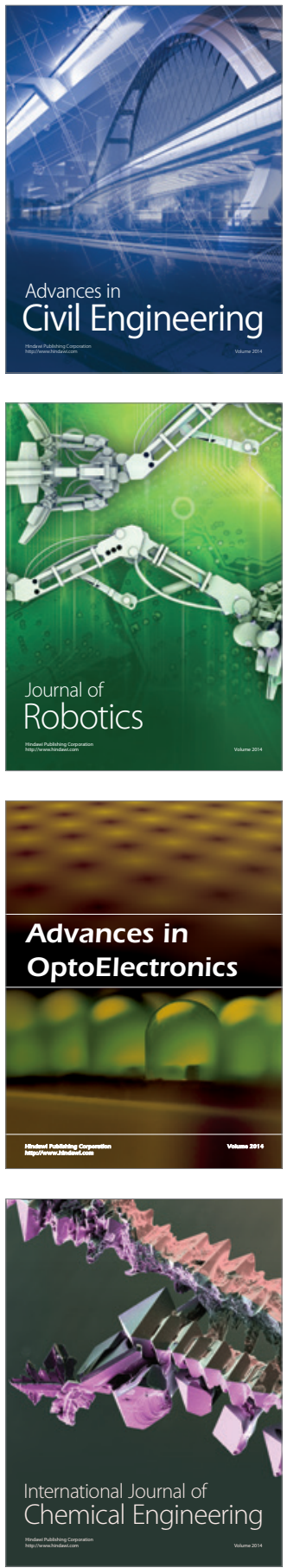

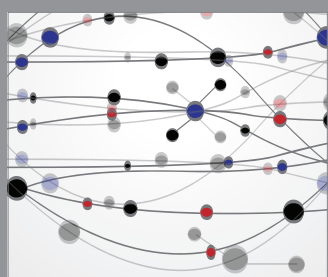

The Scientific World Journal

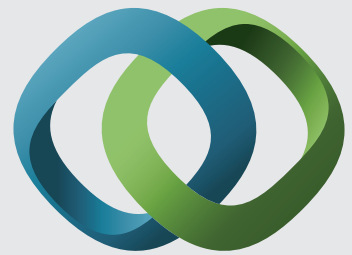

\section{Hindawi}

Submit your manuscripts at

http://www.hindawi.com
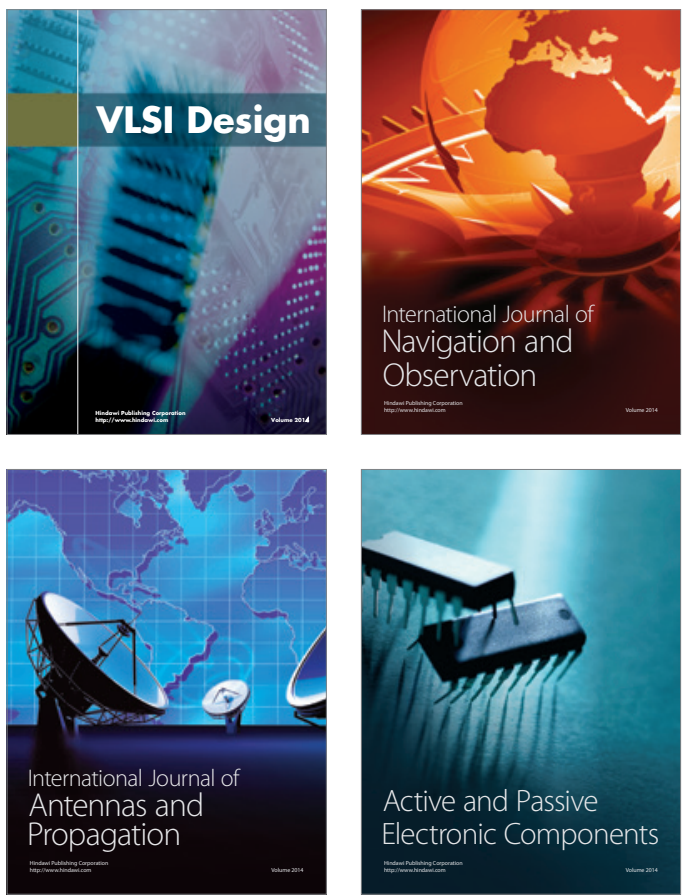
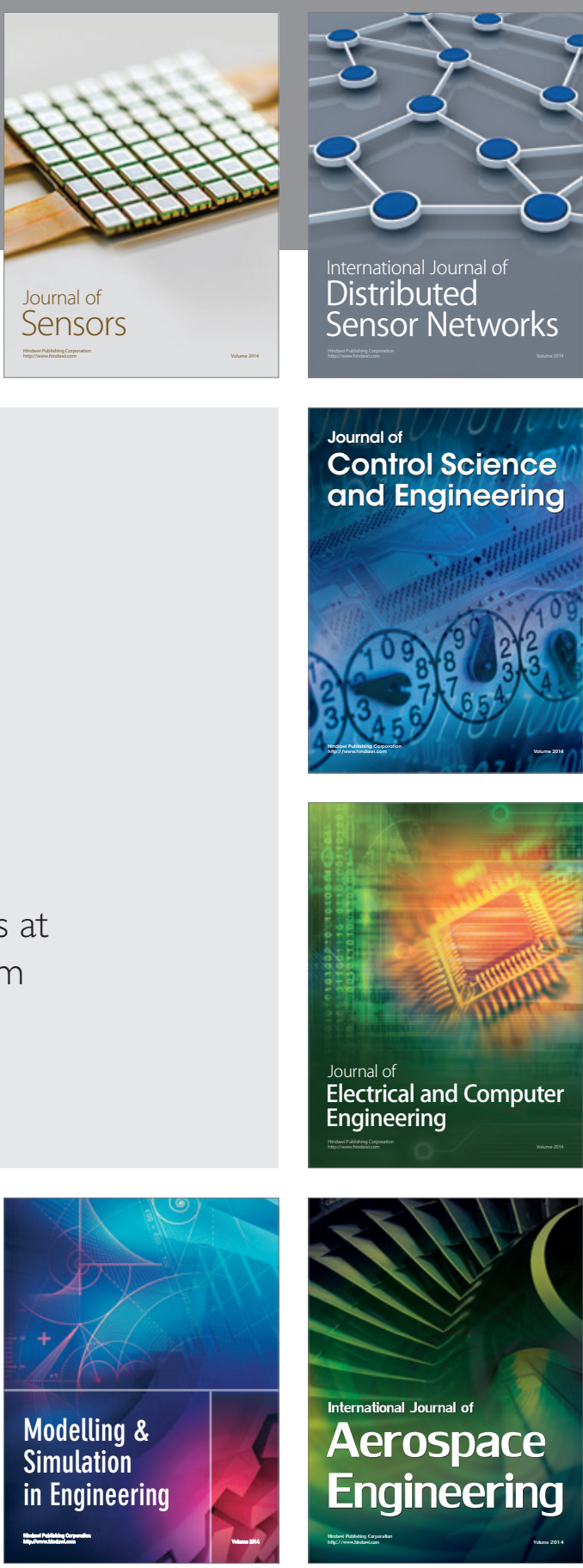

International Journal of

Distributed

Sensor Networks

Journal of

Control Science

and Engineering
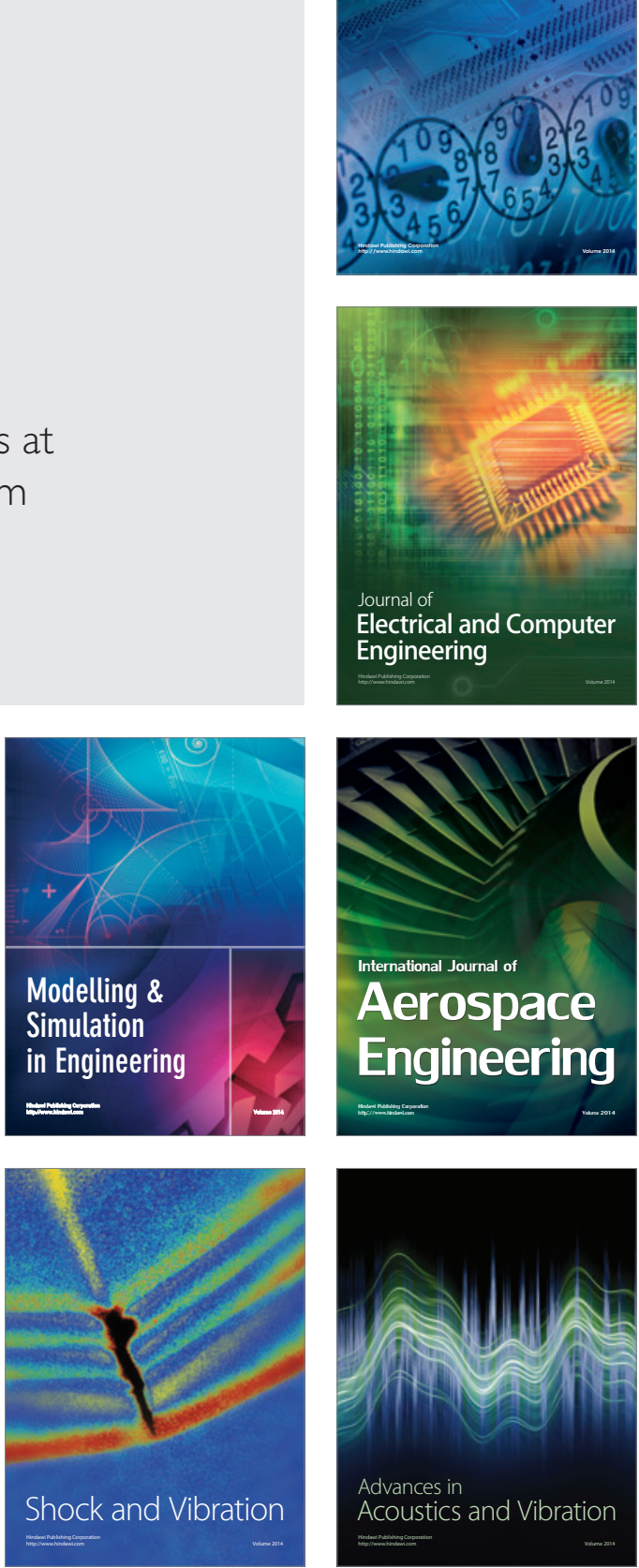